\title{
O matriciamento em saude mental como dispositivo para a formação e gestão do cuidado em saúde
}

\author{
| ${ }^{1}$ Angela Maria Santos, ${ }^{2}$ Antonio Ledo Alves Cunha, ${ }^{3}$ Paula Cerqueira |
}

Resumo: Este trabalho tem como objetivo refletir a partir da pesquisa realizada no município de Piraí-RJ sobre o processo de matriciamento e suas implicaçóes para a gestão do cuidado em saúde. Utilizando a cartografia como referencial metodológico, foi possível trabalhar o tema do matriciamento, junto aos estudantes/ bolsistas do projeto PET saúde (Programa de Educação para o Trabalho em Saúde), exercitando o processo de implicação e responsabilização como atores operadores do cuidado em saúde. Os pesquisadores foram se dando conta de que na produção da saúde, a definição por um modelo de atenção, por parte do gestor, não é suficiente para determinar a execução dos princípios do SUS.

Nesta perspectiva, o matriciamento foi se caracterizando como importante ferramenta para mudança gerencial dos serviços de saúde, considerando seu potencial para modificar a lógica hierarquizada da gestão em saúde e para a integração das açóes de saúde mental na atenção primária em saúde. Nesse percurso, as formulações apresentadas ajudam a compreender o matriciamento como um dispositivo para a produção de subjetividades para a gestão do cuidado em saúde.

> Palavras-chave: matriciamento; saúde mental; cuidado em saúde; gestão; SUS.

\author{
1 Universidade Federal do Rio de \\ Janeiro. Rio de Janeiro-RJ, Brasil \\ (angleal@globo.com). \\ ORCID: 0000-0002-0393-711x \\ ${ }^{2}$ Universidade Federal do Rio de \\ Janeiro. Rio de Janeiro-RJ, Brasil \\ (acunha@hucff.ufrj.br). \\ ORCID: 0000-0003-3592-1849 \\ ${ }^{3}$ Universidade Federal do Rio de \\ Janeiro. Rio de Janeiro-RJ, Brasil \\ (paulacerqueiraufrj@gmail.com). \\ ORCID: 0000-0002-5811-3302
}

Recebido em: 25/03/2020 Aprovado em: 28/08/2020 Revisado em: 05/10/2020 


\section{Introdução}

O Sistema Único de Saúde brasileiro (SUS) é um dos maiores e mais complexos sistemas de saúde pública do mundo, abrangendo desde o simples atendimento para avaliação da pressão arterial, por meio da Atenção Básica, até o transplante de órgãos, garantindo acesso integral, universal e gratuito para toda a população do país. Com a sua criação, o SUS proporcionou o acesso universal ao sistema público de saúde, sem discriminação.

A implantação do SUS requer uma sociedade em que todos os cidadãos tenham assegurado um padrão de vida digno. É difícil se pensar em um sistema de saúde universal e equitativo em um país, como o Brasil, onde a muitos faltam condiçóes de sobrevivência. Todavia, se é difícil ter o SUS legal cabalmente implantado nas atuais condiçôes sociais do país, não é menos difícil reverter esse quadro sem uma política de saúde baseada nos princípios de universalidade e equidade. Na verdade, o SUS é uma estratégia das mais importantes para a construção de um país socialmente justo.

Desta forma, a partir da década de 90, novas exigências são postas à organização do trabalho em saúde. Um novo paradigma passa a ser planejado, com o intuito de reverter o quadro das práticas vigentes, em que os profissionais atuavam de forma fragmentada, hierarquizada e isolada. A saúde passaria a ser considerada sob sua determinação histórica e social. Com o desenvolvimento das políticas e do SUS, a rede de saúde começa a incluir em seu sistema, ainda nos anos 1990, equipamentos como os Centros de Atenção Psicossocial (CAPS) e o Programa Saúde da Família (PSF). A Estratégia de Saúde da Família teve sua implantação realizada de forma gradativa.

A Política de Saúde Mental (2003) e a Política de Humanização do Ministério da Saúde (2004) já preconizavam o apoio matricial como dispositivo de intervenção junto à Atenção Básica, pautado pela noção de território, intersetorialidade e integralidade. Com a criação dos Núcleos de Apoio à Saúde da Família (NASF), institucionalizouse o apoio matricial como ferramenta de trabalho na saúde da família.

Conforme determina a portaria que criou o NASF, os núcleos devem ser constituídos por equipes formadas por profissionais de diferentes áreas do conhecimento, atuando de forma compartilhada e dividindo, com as equipes de saúde da família, a responsabilidade pelas ações de saúde no território onde atuam. O objetivo do NASF é contribuir para a integralidade do cuidado aos usuários do SUS, principalmente por intermédio da ampliação da clínica, auxiliando no aumento da capacidade de análise 
e de intervenção sobre problemas e necessidades de saúde, tanto em termos clínicos quanto sanitários (BRASIL, 2008). Portanto, o trabalho do NASF está estruturado em duas dimensôes: retaguarda clínico-assistencial e apoio técnico-pedagógico. Deve contribuir no processo de educação permanente das equipes apoiadas, na perspectiva de ampliação do cuidado e qualificação do trabalho.

O apoio matricial possibilita o desenvolvimento de habilidades dos profissionais envolvidos, bem como o acesso a outras informaçôes, à construção de novas estratégias de intervenção, à corresponsabilização e ao fortalecimento do trabalho interdisciplinar. Nessa direção, estas políticas apontam a necessidade de integração da saúde mental ao cotidiano das práticas da Atenção Básica para a efetivação da integralidade do cuidado em saúde.

Com o objetivo de superar as práticas fragmentadas e burocratizadas em saúde, Campos (1999) propôs os arranjos organizacionais e metodológicos, apoio matricial e equipe de referência. "O apoio matricial tem uma dimensão de suporte técnicopedagógico, pressupóe apoio educativo para a equipe de referência e açôes realizadas conjuntamente com ela" (CAMPOS et al., 2014, p. 989).

O campo da saúde mental possibilita a descentralização das açôes no território, a capacitação das equipes de referência, a interdisciplinaridade, a retaguarda especializada, modificando a lógica do sistema de referência e contra referência. O matriciamento em saúde mental surgiu, então, como importante estratégia para fazer valer tal articulação, de modo a garantir um cuidado ampliado, por meio da interação dialógica entre os diversos saberes indispensáveis à produção de saúde. Assim, o matriciamento se afirma como recurso de construção de novas práticas em saúde mental também junto às comunidades, no território onde as pessoas vivem e circulam, pela sua proposta de encontros produtivos, sistemáticos e interativos entre equipes da Atenção Básica e equipes de saúde mental.

No entanto, a efetivação dessas práticas enfrenta desafios importantes: mudanças nas relaçôes de trabalho - historicamente hierarquizadas; mudança no modo fragmentado de se operar o cuidado em saúde; mudança na formação em saúde - centrada na perspectiva biomédica; mudança no modo de praticar saúde - que transcende o setor saúde. A questão que se apresenta então é: qual o caminho para se consolidar esta prática?

Este trabalho não toma como ponto de partida uma definição do que é matriciamento; ao contrário, o toma como uma imagem objetivo, ou seja, como 
uma situação ideal a ser alcançada. Tem como objetivo refletir, a partir do percurso desenvolvido em uma pesquisa realizada durante o projeto PET saúde, sobre o processo de matriciamento e suas implicaçóes para a gestão do cuidado em saúde.

Em 2007, o Programa de Reorientação da Formação Profissional em Saúde (PRO-Saúde) foi elaborado pelo Ministério da Saúde em parceria com o Ministério da Educação, tendo como objetivo incentivar transformaçôes processo de formação, geração de conhecimentos e prestação de serviços à população, para abordagem integral do processo de saúde-doença. O Programa de Educação pelo Trabalho para a Saúde (PET-Saúde) caracteriza-se como uma estratégia do PróSaúde, para fomentar a formação de grupos de aprendizagem tutorial em áreas prioritárias para o SUS, inserindo os estudantes das graduaçôes em saúde nos espaços dos serviços (BRASIL, 2010).

Se o Pró-Saúde foi estruturante para promover mudanças institucionais e o deslocamento da área da saúde da universidade, de dentro de seus muros, para a integração com a comunidade e suas necessidades no SUS, o PET-Saúde reforçou esse movimento, conferindo maior concretude ao processo por meio de projetos diretos de intervenção com base em diagnóstico situacional do território. Neste sentido, o PET-Saúde ajudou a introduzir o componente pesquisa, em especial a pesquisa clínica, a pesquisa-ação, a pesquisa sobre ensino e aprendizagem e sobre a gestão dos serviços da saúde. Esse componente, juntamente com o ensino-aprendizagem incorporado aos serviços e ao processo de trabalho em saúde, tem contribuído decisivamente para qualificar a atenção à saúde prestada, e isso está evidenciado em estudos comparativos já publicados.

A pesquisa "PET-Saúde: o matriciamento em saúde mental no município de Piraí: desafios e possibilidades" foi desenvolvida no município de Piraí-RJ, no período 2012-2014, pelo grupo PET Saúde - UFRJ/Psicologia, a partir de uma demanda apontada pela secretaria municipal de Saúde. Buscou avaliar a consolidação de novos paradigmas de atenção à saúde mental, compreendendo que estes dependem das possibilidades de reinvenção da atuação em comunidades. A pesquisa foi devidamente registrada e aprovada pelo Comitê de Ética sob o protocolo no 95/13.

\section{Percurso metodológico}

A construção metodológica desta pesquisa foi composta por diversos passos. $\mathrm{O}$ primeiro foi selecionar os estagiários que trabalhariam no projeto PET Piraí, que 
deveriam estar investidos do desejo de se inserir na área da saúde. O segundo passo foi a realização de uma ampla revisão na bibliografia sobre o tema da saúde pública, coletiva, saúde mental, matriciamento e SUS. O terceiro foi a imersão no campo: o encontro com preceptores e com o território. O quarto passo foi o acompanhamento do percurso dos preceptores por meio de reuniôes mensais, no município. O quinto foi o encontro com os usuários, profissionais e gestores, por meio de entrevistas semiestruturadas. O sexto foi o acompanhamento do percurso dos estagiários através dos momentos de supervisão semanal e dos portfólios individuais e de grupo, pelos quais procuramos identificar as situaçóes de impasses cotidianos e a forma como se produziram as práticas no cotidiano do trabalho.

No intuito de não perdermos o foco, o olhar foi direcionado para a saúde mental e sua conexão com a atenção básica, por meio de entrevistas, que tinham como objetivo conhecer as práticas e concepçôes do matriciamento em saúde mental, trazidas pelos profissionais da atenção básica e da saúde mental, usuários e gestores. Foram utilizados roteiros de entrevistas semiestruturadas. Participaram da pesquisa 14 gestores da Secretaria Municipal de Saúde, 66 usuários, todos os profissionais de saúde mental do CAPS e os profissionais de seis Unidades de Saúde da Família, exceto os agentes comunitários de saúde, que foram limitados a dois nas unidades menores e três nas maiores. Durante a pesquisa, o município não contava com nenhum NASF, cabendo ao CAPS a articulação entre a atenção básica e a saúde mental.

Tratou-se de uma pesquisa qualitativa. A cartografia foi tomada como possibilidade de estudar a complexidade do fenômeno, aproximando vida e pesquisa. Segundo Romagnoli (2009), a cartografia pode ser definida como um modo de conceber a pesquisa e o encontro do pesquisador com o campo. Tem como objetivo acompanhar processos que acontecem em alguns cenários, cujo interesse é investigar a forma pela qual foi possível chegar a determinado resultado, mais do que aferir o resultado final. Assim, esta pesquisa aconteceu onde a realidade se dá, na cena do acontecimento, com os atores envolvidos nele, definidos aqui como protagonistas do processo de investigação.

Além disso, torna-se importante registrar que a metodologia utilizada operou com a perspectiva da constituiçấo do sujeito pesquisador no mundo, ou seja, formas de produzir conhecimento, na qual o mundo e a vida estão em conexão com o objeto a ser pesquisado (CERQUEIRA et al., 2014). Nesta perspectiva, a implicação é intrínseca à produção do conhecimento. Segundo Lourau (2004), o conceito de 
implicação consiste na produção de questionamentos sobre a prática do pesquisador, in mundo. Neste caminho, de acordo com Cerqueira et al (2014), abre-se um espaço para a experiência, para o exercício de produzir um conhecimento interessado, implicado na transformação de práticas e saberes que prescrevem formas universais de se andar a vida. A construção do conhecimento se processa como ativadora e produtora de intervenção na vida. A vida como algo capital, a vida como produção e expressão de subjetividades (GUATTARI, 1992).

De acordo com Soares e Miranda (2009), entendendo que subjetividade é tudo aquilo que concorre para a produção de um "si" e que é constantemente produzida, é fundamental trabalhar por novos campos de possibilidades, inventando no cotidiano novos modos de existências, novas relaçóes consigo mesmo e com o mundo. É neste sentido que tomamos o matriciamento como uma possibilidade de produçáo de novas subjetividades para o cuidado e a gestão em saúde.

Considerando que não é intuito deste trabalho tratar de todas as nuances da pesquisa, visto que esta possibilitou olhares ampliados sob a relação da Atenção básica com a Saúde Mental, em Piraí, será dado destaque àquelas que se relacionam, diretamente com o objetivo mencionado acima.

\section{O encontro como produção de conhecimento na disputa por um sistema de saúde que respeite a vida}

O início do projeto foi caracterizado de forma unânime, por todos os alunos, seja nos seus registros individuais ou nas produçóes de grupo, como um momento de extremo impacto, face ao distanciamento teórico e prático das temáticas apresentadas.

Caos, novidade, sensação de estar perdido, sem entender nada; receio de encarar o campo; falta de conhecimento. (portifólio individual-aluno C).

SUS/Saúde pública, ideia de ambulatório. Caos, superlotação, desintegração. (Portifólio grupal).

Através de palavras e falas curtas os alunos somente expressavam indignação, insatisfação com um sistema que não atende às demandas da população. Estudantes em processo de graduação reproduziam sem embasamento teórico, sem reflexões, sem comprometimento com uma formação que poderá levá-los a trabalhar no SUS. Melhor dizendo, sem nenhuma implicação com a produção do cuidado em saúde.

A apresentação da pesquisa PET aos bolsistas de psicologia transitou, inicialmente, pela aproximação com o SUS, com o mundo do trabalho e é claro com as reflexôes 
sobre o matriciamento. De acordo com o portfólio grupal produzido pelos bolsistas, este início foi marcado por diversos sentimentos. Alguns se sentiam receosos, perdidos em meio ao imaginário social de um caos. Esse caos foi vivenciado de diferentes maneiras. Para uns, estava baseado na situação do sistema de saúde do Rio de Janeiro, ou seja, a superlotação, a longa espera pelo atendimento, a imagem de uma equipe de saúde desintegrada; para outros, esse caos adveio do encontro entre as dúvidas que iam surgindo no estágio e o sistema de saúde como se apresentava.

O espaço da supervisão (momento de reflexão sobre a prática - tutor e alunos bolsistas) ocupou lugar fundamental, para promover o encontro de diferentes pontos de vista e vistas do ponto de maneira produtiva e construtiva: somando e não excluindo e hierarquizando. Dessa forma, foi possível pensar o matriciamento como um exercício de "desterritorialização" e, portanto, como um arranjo para a organização das práticas de cuidado em saúde e gestão. Assim, foi-se produzindo um conjunto de movimentaçóes, formando então um coletivo desejante composto por 19 alunos e um tutor. Nesse percurso, foram produzidas ideias-conceitos, ferramentas, sentimentos, como parte de uma teorização fabricada em processo. Assim, nesses percursos formativos, a "caixa de ferramentas" foi sendo composta.

De acordo com Merhy (2013, p. 176), "a caixa de ferramenta é representada por valises, trazendo a imagem das ferramentas tecnológicas, como saberes e seus desdobramentos materiais e não materiais que fazem sentido de acordo com os lugares que ocupam no encontro". Este processo, ainda no território da Universidade, foi fundamental para a construção de novas narrativas sobre SUS, cuidado em saúde, encontro etc.

\section{O cenário como produtor de afetaçóes}

Inicialmente, a chegada no território se deu por meio da inserção nas rotinas diárias dos respectivos preceptores (psicólogos), seja nas unidades de saúde ou nas atividades do CAPS. Cabe ressaltar que todos os psicólogos compóem a equipe de saúde mental do CAPS, alguns com açóes matriciadoras nas Unidades de Saúde da Família.

Entender que a inclusão das açôes de saúde mental na atenção básica possibilita avançar no processo de desinstitucionalização contribuiu para a desmistificação da loucura, estratégia importante para a construção de uma clínica do cuidado que foi um passo importante para que se continuasse apostando nos encontros entre os atores da pesquisa. Assim, esses temas eram tomados em análise com base em suas experiências, 
no vivido, no experimentado nesses múltiplos territórios que passaram a habitar em Piraí. Segundo Franco e Merhy (2013), pensar é experimentar, é problematizar. O saber, o poder e o si são a tripla raiz de uma problematização do pensamento.

A inserção dos bolsistas nas atividades de alguma maneira foi provocando deslocamentos da equipe, já que trouxe para o CAPS, a questão de como articular o matriciamento. Aos poucos o grupo foi conhecendo os profissionais e suas práticas, compreendendo e fortalecendo a tese de que o processo de trabalho náo segue o mesmo padrão, pois as práticas do cuidado se dão de forma singular. Desta forma, foi se constatando, de acordo com Mehry e Franco (2013), que as normas da ESF, que tem como atributo padronizar as condutas dos trabalhadores, de acordo com as regras ditadas para o funcionamento do programa, influenciam as atividades dentro de limites restritos, pois quando estes se encontram em situação de trabalho, na relação com o usuário, ele próprio em ato, é que define como este cuidado se realiza. A entrada no campo se caracterizou, portanto, por todas as conexóes, desejos e afetaçóes produzidas nesse encontro e desencontro de territórios existenciais.

De acordo com Spinoza (2015), entendemos encontro como algo que faz os corpos colidirem mesmo sem contato visceral, direto, físico, mas que altera os corpos, afetando-os, efetuando não só a mistura dos mesmos, mas modificando-os, aumentando ou diminuindo sua potência de ação no mundo, forjada em ato. Foi esta perspectiva do encontro que nos acompanhou durante todo o trabalho no território, desde as ações dos alunos junto aos profissionais da saúde e aos usuários, como também nas diversas reuniôes com os preceptores de saúde mental e com os gestores (gerentes). Nesse sentido, fica evidente como no matriciamento podemos produzir um espaço propício à construção de teorias e práticas, a partir do entendimento das diversidades e da abertura para o encontro com estas, acolhendo as proposiçóes de todos para que o resultado gerado seja articulado.

Após seis meses inseridos na rotina, junto com os respectivos preceptores, conhecendo o território, o grupo iniciou o processo de entrevistas. Cabe ressaltar que a cartografia requer uma escuta e um olhar ampliados, para além do puro conteúdo da experiência vivida, do vivido da experiência relatado na entrevista, e incluam sua dimensão processual, apreendida em suas variaçóes. Sendo assim, o momento das entrevistas também se caracterizou como espaço de encontro e constituiu verdadeiras colisôes de afetaçôes, que não serão tratadas neste trabalho. No entanto, se faz necessário sinalizar que, de alguma maneira, a temática da integralidade, do 
cuidado e sobretudo da implicação foi atravessando os espaços a partir dos encontros proporcionados pelas entrevistas.

Através das análises das entrevistas realizadas, identificou-se uma diversidade de concepçôes de matriciamento. Os profissionais da Atenção Básica o definiram como um suporte ou capacitação, com o intuito de desafogar a atenção secundária, diminuindo os encaminhamentos. Todos os profissionais sinalizaram dificuldades de articulação com o CAPS. Apenas o profissional de psicologia foi reconhecido como referência, para situaçóes de sofrimento psíquico.

As entrevistas com os gestores possibilitaram reflexôes sobre as ações de matriciamento e as possibilidades concretas de reversão de uma prática de gestão historicamente hierarquizada para outra voltada à cogestão. $\mathrm{O}$ modo como esses profissionais gestores entendem a proposta de matriciamento e atuam em relação a ela interfere diretamente na concretização ou não dessa prática em toda sua capacidade de produção de autonomia, de integralidade do cuidado e da intersetorialidade da atenção. Eles definiram matriciamento como processo de capacitação para a melhoria do serviço da equipe. Muitos entendem essa "capacitação" como um caminho para a diminuição da medicalização excessiva e da exclusão destes pacientes no serviço de saúde. Falam sobre a dificuldade de lidar com os pacientes da saúde mental pela falta de conhecimento e pontuam a dificuldade de articulação entre a Atenção Básica e a Saúde Mental.

De modo geral, o matriciamento é apresentado como uma proposta para acabar com a "lógica do especialista" subjacente ao formato dos encaminhamentos clássicos, visando promover a interdisciplinaridade e a corresponsabilização pelo cuidado na atenção primária, com apoio no conhecimento teórico e vivencial compartilhados entre a equipe matriciadora e a equipe de referência da USF. Este modelo se apresentava bastante eficiente e articulado em relação às outras especialidades no período da pesquisa.

As entrevistas com os usuários foram importantes para entender como eles lidavam com as questôes do sofrimento psíquico e como viam esta clínica no município. Eles trouxeram à cena a dificuldade de encaminhamento para o CAPS, bem como demonstraram em suas falas certa "resistência", ou vergonha para tratar do sofrimento mental, na atenção básica, em função da presença dos agentes de saúde, que são moradores do território. Suas falas nos remeteram à questão do estigma em relação à saúde mental e, de certa maneira, a fragilidade do modelo de atenção. 
A implantação das ações de saúde mental na atenção básica surge exatamente como uma possibilidade de construir outros modos de ser e estar com as pessoas em sofrimento psíquico nas ruas, na comunidade e na vida da cidade. Trata-se de cuidar das pessoas onde elas vivem e com isso aproximar a comunidade, a vizinhança, para uma convivência com a loucura, com a diferença, trabalhando, desta forma para a extinção dos efeitos da segregação e do estigma.

Tomar o conceito de território existencial que, no entendimento de Deleuze e Guattari (1995), é constituído a partir da história e subjetividade de cada indivíduo, abrangendo dessa forma, clínica, espaço físico e subjetividade, pode produzir processos de convivência com a diferença e, por isso, apresentar-se como oportunidade para a diminuição dos preconceitos e estigmas, o que beneficia o processo de recuperação das pessoas.

O município de Piraí conta apenas com um CAPS, onde estão lotados todos os profissionais de saúde mental. Apenas os psicólogos matriciadores tinham atividades, nas unidades de saúde da família, ligadas a este tema. Estes identificaram o matricialmente como uma troca de saberes que pode auxiliar no acompanhamento de um mesmo usuário por toda uma rede de atenção. Tal ideia corrobora a proposta primordial desta estratégia matricial, que apregoa a conquista de ações compartilhadas, interdisciplinares e integradas para a concretização da integralidade do cuidado. Para tanto, faz-se essencial construir relaçóes de confiança e respeito entre os profissionais, de modo que o contato entre os diversos setores e atores, imprescindíveis nesse cuidado, se estruture entre pessoas que acreditam na potencialidade do outro, na sua contribuição e no seu trabalho para um objetivo em comum: a promoção da saúde. Os dois psiquiatras do CAPS não demonstraram implicação com o matriciamento, justificando a dificuldade de tempo para reuniôes ou outras atividades em função da agenda diária de atendimento. Os outros profissionais demonstraram desconhecimento da proposta de matriciamento ou a identificaram como um processo de orientação aos profissionais da atenção básica.

Nas falas de todos os profissionais de saúde chama a atenção que os entraves apontados ao fortalecimento do matriciamento indicam a dificuldade de efetivação de encontros pautados na troca e na construção de parcerias efetivas para a promoção à saúde: algumas unidades não funcionam na lógica da ESF, as quais não conseguem garantir as reunióes das equipes para a integração do cuidado; há limitaçôes de transporte para locomoção dos profissionais de um serviço a outro para 
efetivação do encontro; existe dificuldade de conciliação de agendas entre os serviços para discussão conjunta; falta encontro entre os matriciadores; há dificuldades relacionais entre os envolvidos (que os distanciam); existem equívocos de demanda ao matriciamento por dificuldade de alinhar entendimentos, entre outros.

Inicialmente nos perguntamos: por que é tão difícil garantir e manter esses momentos de encontro produtivo, já que estão assegurados pelas políticas que instituem a Atenção Básica e os CAPS, como momentos de discussão da clínica? Além disso, a própria lei regulamentadora do SUS garante tal integração entre profissionais e serviços, ao destacar em seus princípios a intersetorialidade e a integralidade da atenção, que não se sustentam sem essas possibilidades de encontros produtivos. Contudo, mesmo assim as dificuldades de manter esses encontros persistem. Por outro lado, somente um fazer interativo possibilita o cuidado integral, efetivamente produtor de saúde, já que entendemos saúde como um amplo espectro de fatores ligados à vida, em que um único saber e prática jamais conseguirão assegurá-la. Tudo isso só é possível a partir do encontro, obstaculizado por uma sociedade regulada pela lógica capitalista, a qual incentiva a fabricação de um sujeito competitivo e individualista em detrimento de princípios solidários (ONOCKOCAMPOS; GAMA, 2008).

Neste processo de encontro com os diversos atores, através da imersão nas rotinas e dos momentos proporcionados pelas entrevistas, o tema do matriciamento foi deixando de ser apenas conceito representação e passou a funcionar como dispositivo capaz de acionar novas relações, novas discussóes, novas caminhadas e novas possibilidades orientadas pelo cuidado, pelo trabalho em equipe e atenta ao contexto que envolve o adoecimento dos sujeitos.

As narrativas produzidas pelos participantes da pesquisa, de modo geral, apontam a necessidade de se estruturar e articular ferramentas que possibilitem a produção de novas subjetividades para o SUS. Nesse cenário, são essenciais as açôes de educação permanente, que se caracterizam pela aprendizagem no trabalho e para o trabalho. É uma concepção que norteia, no cotidiano, açôes voltadas para o saber prático e transformador, pautada na interdisciplinaridade. $\mathrm{O}$ apoio matricial pode se constituir em uma importante ferramenta de trabalho e um mecanismo privilegiado de educação permanente em saúde, pois está pautado na interprofissionalidade, trabalho em redes, atuação em território definido, compartilhamento de saberes e deliberação conjunta. 
Ao fim da pesquisa PET, foram apresentadas discussóes envolvendo a coordenação de atenção básica, coordenação de saúde mental e a gestão-secretaria municipal, sobre importantes mudanças alcançadas pelo trabalho. A principal delas foi certa aproximação entre as coordenaçôes. As ações da pesquisa foram reconhecidas como uma iniciativa ao matriciamento em saúde mental no município, buscando primordialmente a produção de outra cultura no setor da saúde e sujeitos mais inventivos, participativos, ativos, críticos e solidários, ao contrário de uma perspectiva tradicional, corporativista e alienante do profissional.

\section{Surpreendendo a pesquisa PET: quando o dispositivo surpreende o instituído de uma pesquisa}

Segundo Deleuze (1996), dispositivo é um conjunto de múltiplas linhas, de diferentes naturezas que seguem diferentes direçóes, formando processos sempre em desequilíbrio. De um modo geral, os dispositivos estão sempre produzindo objetos, sujeitos, práticas e Deleuze os percebe como máquinas de fazer ver e de fazer falar. Assim, os dispositivos têm por componentes linhas de visibilidade, linhas de enunciação, linhas de força, linhas de subjetivação, linhas de brecha, de fissura, de fratura, que se entrecruzam e se misturam.

Durante os dois anos de pesquisa, foi possível perceber as diversas faces do processo de trabalho em saúde e a potência dos encontros proporcionados pela ideia do matriciamento. O grupo de pesquisa foi se aproximando, então, da ideia de um apoio matricial rizomático (BERTUSSI, 2010). O devir rizomático não é uma sequência linear direcionada ao avanço contínuo, "um rizoma pode ser rompido e quebrado em um lugar qualquer, mas também retoma segundo uma de suas linhas ou segundo outras linhas" (DELEUZE; GUATTARI, 1995, p. 17). Neste sentido, o matriciamento rizomático encontra-se no campo da micropolítica. Segundo Foucault (1979), o conceito de micropolítica refere-se ao poder como técnica de subjetivação, como espaço vivo em que se produzem as relaçôes. Deve ser compreendido como espaços de construçôes desmontáveis e conectáveis que se abrem para o ilimitado.

Para operar nesse modelo, é importante romper os muros disciplinares e estabelecer novos modos de encontro entre os diferentes saberes e fazeres. De acordo com Bertussi (2010), é fundamental reconhecer que é no cotidiano das instituiçôes de saúde que estão as convocaçôes, as demandas e os problemas. E nesses espaços vão se operando os diferentes meios ou modos de produção de cuidado e de regulação. 
Essas consideraçôes têm consequências para as atividades de pesquisa, mas também sobre o agir de gestores e profissionais de saúde em seus encontros com os usuários. A gestão de saúde de Piraí se caracterizava, no momento da pesquisa, por ser comprometida com a implantação e o fortalecimento do SUS. Encontrava-se com dificuldades em relação à coordenação de saúde mental e vinha tentando investir em uma coordenaçấo de pessoas, em função dos conflitos vivenciados no dia a dia da gestão, que dificultava a integração entre as equipes, principalmente entre a saúde mental e a atenção básica. Por sua vez, os profissionais da saúde mental e os da atenção básica encontravam-se "mobilizados frente aos conflitos, divergências e sofrimento frente a um trabalho desafiador, que causa inúmeros incômodos e desconfortos, uma vez que ao se dispor estar com o outro no território, o profissional se depara com as mais variadas questôes de sofrimento e realidades sociais, que extrapolam sua governabilidade de ação. É muito incômodo sair do seu lugar de conforto. Ir ao território significa se deparar com a angústia, com o caos, com a impotência.

O encontro com o território vai desnudando outro modo de operar o cuidado que em nada se aproxima das orientaçóes e dos protocolos instituídos. Diante de suas vivências, os profissionais seguem desenvolvendo suas atividades, de acordo com suas possibilidades. Talvez por esta razão, o processo de trabalho em saúde não possa ser controlado plenamente por lógicas gerenciais, pois é um trabalho vivo realizado em ato com autonomia dos trabalhadores e um grau de liberdade significativo no modo de produzir os atos de saúde, decorrente da relação privada que estabelecem com o usuário. Os profissionais têm um espaço próprio de gestão de seu trabalho (FRANCO, 2003).

É preciso sinalizar que nenhum modelo que tente difundir-se como uma estratégia político-institucional é capaz de mudar a forma como são prestadas as açôes de saúde e geridas as políticas de saúde. É preciso admitir que os modelos portam lógicas distintas que podem favorecer ou não a qualificação da atenção à saúde e a transformação dos modos hegemônicos de produção da saúde; que podem ou não dar respostas aos princípios da universalidade de acesso, integralidade, atenção e equidade nas estratégias de acolhimento e encaminhamento de soluçôes. Não se trata de defender uma ausência de gestão, mas há que se considerar que a gestão não consegue controlar o cotidiano, pois não há regra e norma que possam controlar a totalidade dos espaços dos processos individuais de trabalho dos profissionais de saúde. 
Utilizamos o conceito de gestão peripatética produzido por Baduy (2010) como ferramenta para dar sentido às conversaçóes e pensamentos que acontecem em corredores e em salas de café, nos vários ambientes, para enfatizar que a gestão está em todos os lugares. De acordo com Merhy e Feuerwerker (2009), todo ator em situação de governo encontra diante de si outros atores que também governam e disputam com ele a direcionalidade da ação, utilizando para isso os recursos de que dispóem. É verdade que os atores em situação de governo dispóem de maior controle sobre recursos, mas eles precisam saber governar e necessitam, para isto, de uma caixa de ferramentas que compóe sua capacidade de governar.

Neste ponto, retomamos a experiência da pesquisa PET, que foi se desenvolvendo em um movimento de construção e desconstrução coletiva, caracterizando um verdadeiro processo de subjetivação para o trabalho em saúde no SUS. Este caminhar foi apontando que a solução macropolítica, por si só, sempre será insuficiente se não operarmos desvios nas formas de se produzir saúde. No final do trabalho. foi possível perceber como a pesquisa se consolidou como um exercício de matriciamento, entendendo que este precisa ser fundamentalmente micropolítico, pois é nesse território que entram as relaçôes de poder, a caixa de ferramentas e as afecçôes. Apenas neste espaço micropolítico é possível transitar nos territórios recheados por desejos, projetos e intencionalidades possibilitando o encontro entre o conjunto dos profissionais de saúde, para a reflexão de suas açôes, propiciando a eles a oportunidade de interinventar em si mesmos, ativando a produção singular do encontro com usuários e trabalhadores da sua e de outras unidades de saúde.

Foi possível perceber que, da mesma maneira que os estudantes bolsistas foram se produzindo enquanto operadores do cuidado em saúde, os profissionais da saúde mental puderam caminhar para o reconhecimento de suas potencialidades para a proposição de açôes gestoras, compreendendo a importância de estarem envolvidos na criação de estratégias, citando seus compromissos com as políticas públicas e sobretudo apostando na integralidade do cuidado. A integralidade remete à capacidade de dar respostas e encaminhamentos singulares. Neste sentido, o eixo da integralidade pode ajudar na compreensão da autogestão dos coletivos para superar a modelagem de serviços centrados em procedimentos, de usuários interpretados como peças orgânicas ou como o simples território onde evoluem os quadros fisiopatológicos e de doenças enfrentadas como eventos biológicos. Este percurso também foi fundamental para o exercício de implicação e empoderamento dos profissionais no sentido do se 
reconhecer como atores importantes na gestão do cuidado em saúde. Dessa maneira, além de processos que permitam incorporar tecnologias e referenciais necessários, é preciso implementar espaços de discussão, análise e reflexão da prática no cotidiano do trabalho e dos referenciais que orientam essas práticas.

Para além dessas questôes, a gestão (gerência) deve ter o compromisso de dar suporte, de criar instâncias de análise para as equipes, ajudando a compreender que o turbilhão de emoçôes que acompanham o processo de trabalho é inseparável de nossa condição de humanidade. De acordo com Kaës(1991), sofremos também, na instituição, por não compreendermos a causa, o objeto, o sentido e a própria razão do sofrimento que aí experimentamos.

O cuidado só acontece quando entramos em um nível de encontro no qual podemos expor nossos não saberes, nossas angústias frente à demanda com que não sabemos lidar. Geralmente, um ato de cuidado dentro da rede não ocorre, justamente, porque os profissionais nunca sentiram/pensaram/conheceram aquilo que, inusitadamente, aparece a sua frente para atender. Afinal, sentem-se despreparados, desfiliados de seu saber profissional. E nesse mal-estar que o não saber traz, o recorrente é colocar-se em uma postura defensiva frente ao cuidado a ser efetivado, no qual escondemos nossa fraqueza e a limitação de nossa formação. Talvez por isso, como aponta Belotti (2012), muitos profissionais de saúde se fixam em protocolos e normas que determinam os comportamentos e condutas, aprisionando seus atos de cuidado com o usuário em um padrão previamente estabelecido.

No entanto, o interessante é que justo no encontro com o limite dos protocolos e de nossas frágeis formaçóes que nos deparamos com a maior potência, isto é, com a possibilidade de adquirir novos saberes, experimentaçóes que se apresentam para movimentarmos a aprendizagem táo dura e protocolada advinda da academia corporativa e de tantos bancos escolares. Na realidade, a prática do trabalho vivo, em ato, nos joga para um processo de "desaprendizagem", abrindo a possibilidade de ocupar esse vazio produzido com novos sentidos nesses encontros-acontecimentos (MERHY, 2013). Assim, constituímos equipes multiprofissionais, coletivos de trabalho, lógicas apoiadoras e de fortalecimento e consistência de práticas uns dos outros nessa equipe, orientadas pela sempre maior resolutividade dos problemas de saúde das populaçóes locais ou referidas ou colocamos em risco a qualidade de nosso trabalho, porque sempre seremos poucos, sempre estaremos desatualizados, nunca dominaremos tudo o que se requer em situaçôes complexas de necessidades em/direitos à saúde. 
Merhy (1997) afirma que um dos grandes nós críticos que vêm sendo debatidos no campo da Saúde Coletiva é justamente o modo como são estruturados e gerenciados os processos de trabalho nos diferentes tipos de estabelecimentos de saúde. $\mathrm{O}$ autor aponta que a busca da mudança do modo de se produzir saúde deve apostar que esta é uma tarefa coletiva do conjunto dos trabalhadores e que não está somente na dependência de reformas macroestruturais e organizacionais. Nesse sentido, trata da micropolítica do trabalho vivo em saúde, colocando como desafio central a produção de uma reforma publicizante do sistema de direção dos serviços, implicando uma coletivização da gestão dos processos de trabalho em saúde cotidianamente, tomando como referência o interesse e as necessidades dos usuários.

A introdução desta abordagem retiraria os trabalhadores da condição de "recursos" para o estatuto de atores sociais das reformas, do trabalho, das lutas pelo direito à saúde e do ordenamento de práticas acolhedoras e resolutivas de gestão e de atenção à saúde.

\section{Considerações finais}

As formulaçóes apresentadas ajudam a entender o matriciamento como um dispositivo para a produção de subjetividades para a gestão do cuidado em saúde. A dinâmica que envolve os processos de trabalho é profundamente complexa, tendo em vista o conjunto dos autogovernos em operação, as cabeças presentes e o jogo de interesses organizados como forças sociais que atuam na micropolítica do processo de trabalho. É necessário compreender, nessa complexidade, os distintos governos micro e macro que operam nos cenários.

Para compreender a complexidade que envolve o território da gestão no setor de saúde, não há como deixar de adentrar o estudo da micropolítica. É muito comum, no cotidiano da saúde, prevalecer o entendimento de que tudo acontece em razão de maus ou bons governantes. O contrário também acontece; isto é, culpam-se os trabalhadores pelas mudanças que não acontecem, ou a sua formação, que não os preparou para práticas transformadoras.

O que configura uma prática, entretanto, não são iniciativas do governo ou modos de atuar dos trabalhadores como fatores em oposição. Sem construir um processo de trabalho que eleve a implicação dos trabalhadores com seus cotidianos tomados como abertos e sob construçáo coletiva - progressistas ou conservadores não 
se distinguem. Nesta perspectiva, o matriciamento caracteriza-se como ferramenta essencial para uma mudança gerencial dos serviços de saúde, considerando seu potencial para modificar a lógica hierarquizada da gestão em saúde e para a integração das açôes de saúde mental na Atenção Primária em Saúde, estabelecendo inovação das abordagens psicossociais pela assistência compartilhada entre equipe, familiares e usuários. Essas atividades disponibilizam ampliação de acesso e diversificação da atenção à saúde direcionada para a integralidade.

O percurso da pesquisa PET, conforme apresentado, consolidou-se por um exercício de matriciamento junto aos bolsistas (estudantes, preceptores e tutor), propiciando implicação, respeito e responsabilização no cuidado á saúde. Foi nesta direção que tomamos o matriciamento como uma possibilidade de produção de novas subjetividades para a gestão do cuidado em saúde, uma vez que pode constituir um espaço subjetivo conjunto, uma área transicional comum, relativamente operatória um espaço intercessor, como nos diz Mehry (1997). A relação mútua entre os atores envolvidos é, ao mesmo tempo, espaço de construção comum, no caso do cuidado em saúde. Um dispositivo micropolítico potente para um projeto de sociedade, pautado pela solidariedade e o respeito às múltiplas formas de vida que habitam o mundo.

Explorar essas potencialidades pode ser uma realidade possível, mesmo diante de um contexto social, político e econômico extremamente conflituoso como o que se tem vivenciado no Brasil. ${ }^{1}$

\section{Referências}

BADUY, R. S. Gestão municipal e produção do cuidado: encontros e singularidades em permanente movimento. Rio de Janeiro, 2010. Tese (Doutorado em clínica Médica) - Faculdade de Medicina, Universidade Federal do Rio de Janeiro, Rio de Janeiro, 2010.

BELOTTI, M. Encontros de matriciamento: cartografando seus efeitos na rede de cuidados de saúde mental. Dissertação (Mestrado em Psicologia Institucional) - Universidade Federal do Espírito Santo, Vitória, 2012.

BERTUSSI, D. C. O apoio matricial rizomático e a produçâo de coletivos na gestão municipal em saúde. Tese (Doutorado) - Programa de Pós-Graduação em Clínica Médica da Faculdade de Medicina da Universidade Federal do Rio de Janeiro. Rio de Janeiro, 2010.

BRASIL. Ministério da Saúde. Coordenação de Saúde Mental e Coordenaçâo de Gestáo da Atenção Básica. Saúde Mental e Atenção Básica: o vínculo e o diálogo necessários. Brasília: MS, 2003. 
Ministério da Saúde. Núcleo Técnico da política de Humanização. Clínica Ampliada, equipe de referência e projeto terapêutico singular. Brasília. Ministério da Saúde, 2008.

. Ministério da Saúde. Ministério da Educação. Programa Nacional de Reorientação da Formação Profissional em Saúde - PRÓ-Saúde: objetivos, implementação e desenvolvimento potencial. Brasília: Ministério da Saúde; Ministério da Educação, 2007.

CAMPOS, G. W. S. Equipes de referência e apoio especializado matricial: uma proposta de reorganização do trabalho em saúde. Ciênc Saúde Coletiva, v. 4, n. 2, p. 393-403, 1999.

CAMPOS, G. W. S. et al. A aplicação da metodologia Paideia no apoio institucional, no apoio matricial e na clínica ampliada. Interface Interface (Botucatu), v. 18, n. 1, p. 983-995, 2014.

CERQUEIRA, G. et al. Uma pesquisa e seus encontros: a fabricaçáo de intercessores e o conhecimento como produção. In: GOMES, M. P. C.; MERHY, E. E. (Orgs.). Pesquisadores in-mundo: um estudo da produção do acesso e barreira em saúde mental. Porto Alegre: Rede Unida, 2014. p. 25-42.

DELEUZE, G. O que é um dispositivo? In: . O mistério de Ariana. Lisboa, Vega, 1996. p. $83-96$.

DELEUZE, G.; GUATTARI, F. Mil Platôs - capitalismo e esquizofrenia. V. 1. Rio de Janeiro: Editora 34, 1995.

FOUCAULT, M. Microfísica do poder. Rio de Janeiro: Graal, 1979.

FRANCO, T. B.; MERHY, E. E. O reconhecimento de uma produção subjetiva do cuidado. In:______. (Orgs.). Trabalho, produção do cuidado e subjetividade em saúde. São Paulo: Hucitec, 2013. p. 151-171.

FRANCO, T. B. Processos de trabalho e transição tecnológica na saúde: um olhar a partir do Sistema Cartão Nacional de Saúde. Tese (Doutorado) - Universidade Estadual de Campinas, Campinas, 2003.

GUATTARI, F. Caosmose: um novo paradigma estético. Rio de Janeiro: Editora 34, 1992.

LOURAU, R. Análise Institucional. São Paulo: Hucitec,2004.

MERHY, E. E. O cuidado é um acontecimento e não um ato. In: MERHY, E. E., FRANCO, T. B. (Orgs.). Trabalho, produção do cuidado e subjetividade em saúde. São Paulo: Hucitec, 2013. p. 172-182.

MERHY, E. E. O SUS e um de seus dilemas: mudar a gestão e a lógica do processo de trabalho em saúde - um ensaio sobre a micropolítica do trabalho vivo. In: FLEURY, S. Saúde e democracia: a luta do CEBES. São Paulo: Lemos Editorial, 1997. p. 25-41.

MERHY, E. E. FEUERWERKER, L. C. M. Educação permanente em saúde: educação, saúde, gestão e produção do cuidado. 2009. Disponível em: https://edisciplinas.usp.br/pluginfile. php/4448009/mod_resource/content/1/TRABALHO2.pdf Acessado em, 11/10/2020. 
ONOCKO-CAMPOS, R.; GAMA, C. Saúde mental na Atenção Básica. In: CAMPOS, G. W. S.; GUERRERO, A. V. P. Manual de práticas de Atenção Básica: saúde ampliada e compartilhada. São Paulo: Hucitec, 2008. p. 210-236.

KAËS, R. Realidade psíquica e sofrimento nas instituiçôes. In: KAES, R. et al. (Orgs.). A instituição e as instituiçôes. São Paulo: Casa do Psicólogo, 1991. p. 19-56.

ROMAGNOLI, R. C. A cartografia e a relação pesquisa e vida. Psicologia e Sociedade, v. 21, n. 2, 2009. Disponível em: https://www.scielo.br/pdf/psoc/v21n2/v21n2a03 Acesso em: 11/10/2020.

SOARES, L. B.; MIRANDA, L. L. Produzir subjetividades: o que significa? Estudos e Pesquisa em Psicologia. Rio de Janeiro, n. 2, p. 408-424, 2009.

SPINOZA, B. de. Ética/Spinoza. Belo Horizonte: Autêntica Editora, 2015.

\section{Nota}

${ }^{1}$ A. L. Santos: coordenação do projeto de pesquisa que originou este artigo, elaboração delineamento e análise final dos resultados obtidos. A. L. A. Cunha: participação na elaboração do projeto, delimitando os eixos de discussão e análise dos resultados.) P. Cerqueira: orientação na concepção e na metodologia do trabalho, revisão final. 


\section{Abstract}

Matrixing in mental health, as a device for
the formation and management of health care

This work aims to reflect, based on the research carried out in the municipality of Piraí-RJ, on the matrix process and its implications for the management of health care. Using cartography as a methodological reference, it was possible to work on the matrix support theme, with students / scholarship holders of the PET Saúde (Education Program for Health Work), exercising the process of implication and accountability as actors that operate health care. The researchers realized that in the production of health, the definition by a model of care, on the part of the manager, is not sufficient to determine the implementation of the principles of SUS. In this perspective, matrix support was characterized as an important tool for the management change of health services, considering its potential to modify the hierarchical logic of health management and for the integration of mental health actions in primary health care. Along this path, the formulations helped to understand matrix support as a device to produce subjectivities for the management of health care.

Keywords: matrix support; mental health; primary care; care; management; SUS. 